\title{
Appraisal of the Use of Earth for Sustainable Low-Income Housing Construction in Nigeria
}

\author{
Eugene Ehimatie Atamewan, Grace Atah Otire, Innocent Ibi Egbuluwa
}

\section{ABSTRACT}

Earth is indisputably the cheapest and most abundant nature-given building material in the universe. Housing or shelter which is second most important need of man after food has become unreachable and unattainable by the low-income group in developing countries today. This is due to the high cost of building materials and the dependence on contemporary materials which only the rich can afford. Therefore, this paper appraised the applicability of earth as a building material, the advantages and acceptability or otherwise in Cross River State, Nigeria. The method of study includes literature review, participant observation, questionnaire administration and use of focal group discussion. The data obtained was analyzed using simple statistical approach with results presented in tables. Findings revealed that over $85 \%$ of the buildings in the study area are constructed with earth. Also, the level of acceptability of earth material is very high in the study area. The study concluded that more awareness should be created on the use of earth and government agencies should promote earth acceptability by constructing some housing projects using earth.

Keywords: building, construction, earth, housing, low-income, sustainable.

\section{INTRODUCTION}

The housing deficit in most developing countries is alarming and fulfilling the housing requirements or needs of the populace with industrial building materials only is no longer possible hence the reliance on the use of earth for housing solution. Undoubtedly, earth has been the most prevalent and widely used building material ever known to humans. All continents and climates had consistently relied on the use of earth to solve their housing problems [1]. It has been ascertained that about one third of the human population resides in earthen houses; while in developing countries like Nigeria the number is more than one half. Thus, over $50 \%$ of the population in developing countries most of who lives in rural areas and some in urban centres live in houses built with earth [2], [3].

Urbanization with its attendant effects on the built environment such as exploitation of resources, energyintensive production and construction and environmental degradation has necessitated the call for sustainable development through the use of ecological friendly materials such as earth in construction.

Moreover, due to the fact that presently over $90 \%$ of Nigerians within the low-income range cannot afford contemporary housing built with industrial materials even if
Published Online: October 13, 2020

ISSN: $2684-446 \mathrm{X}$

DOI: 10.24018 / ejgeo.2020.1.5.72

Eugene Ehimatie Atamewan*

Department of Sustainable Architecture \& Urban Design, Faculty of Architecture, Cross River University of Technology, Calabar, Nigeria.

(e-mail: atamewaneugene@ ${ }^{@ m a i l . c o m) ~}$

\section{Grace Atah Otire}

Post Graduate Student, Department of Architectural Design, Faculty of Architecture, Cross River University of Technology, Calabar, Nigeria.

\section{Innocent Ibi Egbuluwa}

Post Graduate Students, Department of Architectural Design, Faculty of Architecture, Cross River University of Technology, Calabar, Nigeria.

*Corresponding Author

they saved $100 \%$ of their income for a period of ten years. The implication is that the current housing deficit in Nigeria as well as the wish of the low-income group to own a house of their own cannot be realized [4], [5]. Also, developed nations that have jettison the use of earth in building construction in preference for industrial energy-intensive material in the past decades have since realized that earth or mud, as a natural building material is superior to industrial building materials such as concrete, brick and lime-sandstone due to its numerous advantages on the health of the people and the built environment in general [1].

Personal observation across urban centres in Cross River State and other cities in the South- South region of Nigeria reveal unpleasant sites of uncompleted residential houses by individual of various income groups especially the middle and low-income groups. This is largely due to insistence on use of industrial construction materials. Studies by [6], [7], [8] has shown that the main reason for uncompleted housing project is inadequate funds. Despite the global call by the United Nations and other agencies for the promotion of sustainable development through the use of readily available local building materials including the adaptation of building techniques suitable for local conditions for their availability, cost effectiveness and eco-friendly nature, the Nigerian construction sector and building professionals still promote the use of industrial building materials that are unaffordable 
to many. This could be as a result of ignorance on the advantages of earth as a building material and how to overcome the disadvantages of earth especially durability, workability and aesthetics [3], [9].

This study is therefore aimed at appraising the applicability of earth as a building material, the advantages, overcoming the disadvantages, through stabilizing and the construction techniques for the realization of the dreams and aspirations of the low-income urban dwellers in their quest to have buildings of their own in addition to solving the problem of homelessness using Calabar, Cross River State, Nigeria as a case study.

\section{THEORETICAL FRAMEWORK}

Earth is indisputably the cheapest and most abundant nature-given building material in the universe. The history of shelter or buildings cannot be told without reference to earth as a major material for its realization. Earth is regarded as one of the most extensively used building material ever known to man; this is because earth construction practice has been known to man for over 9000 years. It has been used in all ancient cultures, not only for homes only, but also for religious buildings too [1], [10].

Historically, there are ancient cities such as Akhlet-Aton and Temple of Ramses II in Egypt; Babylon in Iraq; Catal Hunyuk in Turkey; Great Wall of China; Harappa and Mohenjo-Daro in Pakistan; the Sun Pyramid in Teotihuacan, Mexico built thousands of years ago with earth material which still exist till date [11], [1].

In terms of availability, earth is the most abundant readily available and cheapest building material in virtually all regions of the world. It is versatile and can be commonly obtained directly from the building site during the excavation process. In developed countries of the world, earth is no longer seen as a ancient construction material but a modern material due to its sustainability advantages over other construction materials in terms of its cost effectiveness, energy efficiency, flexibility and environmental friendliness hence it has been revived and developed for both residential and industrial construction [10], [12]. Thus, earth could be aptly referred to as 'the most ancient and most modern construction material of all times'.

In developing countries in general and Nigeria in particular, building earth has been the indigenous material for house construction. For centuries, earth has been used for building construction in Nigeria and efforts have been made to develop it to improve both the strength and durability, which are the core disadvantages of earth as a construction material. Most of the available houses in all villages and city suburbs are built with earth material [13], [14]. However, the use of earth in housing construction in developing countries is gradually phasing out and people of the middle and high income group do not even consider it as a building material and surprisingly too, the low-income urban dwellers are toeing same line of thought. This is due to its limitations which according to Daniel et al. (2018) include stigmatization of the users as poorest of the poor, perceived lack of acceptability by public and private sectors reflecting in non utilization in housing projects, high maintenance requirement, among others.

In terms of composition, building earth should contain good mixture of clay and sand rich in mineral content for it to maintain its coherent, plastic, sticky and cementatous properties. The choice of good quality building earth lies in the selection of earth with ideal ratio of clay and sand, with very low silt content as possible. This is because silt particles lies between the particles sizes of clay and sand. Hence, it is practically impossible to get soil or earth with the idea proportion of clay and sand without silt. Clay is the binding material that provides the plasticity and cohesion of the mixture while sand gives the strength of the mixture, silt on the other hand impedes proper functioning of building earth causing poor drainage in earth. This type of building earth can only be found in the mineral part of the soil layer deep in the ground [15], [12].

The type of good building earth with the mixture of clay and sand mineral content in ideal proportion with low silt content is mud. Mud or loam- which is the scientific name for earth is an unfired, untreated or raw earth [15]. Therefore, it is not out of place that most of the houses constructed in most villages across Nigeria were carried out with mud or loam material. But it should be stated that before loam can be used in construction, it has to be worked upon including the mixture with water and this result to the different type of loam used in construction.

Several authors including [1], [9], [15]-[18] have carried out studies on earth as a building material outlining the properties, workability, advantages and disadvantages of earth as follows:

\section{A. Advantages of Earth/Loam}

i. Loam balances air humidity: it absorbs and desorbs humidity thereby maintaining indoor climate and produces healthy living condition.

ii. Loam stores heat: by passive method, controlling and balancing indoor temperature.

iii. Loam reduces environmental pollution and saves energy.

iv. Loam is environmental-friendly and re-usable/ recycled material.

$\mathrm{v}$. Loam is cost-effective saves material and transportation costs.

vi. Loam requires use of simple construction techniques, tools and less skilled labour.

vii. Loam walls absorbs pollutants.

viii. High thermal and sound insulating properties.

ix. Earth construction promotes local culture, heritage, and material.

x. High workability and flexibility.

xi. Earth is available in abundance in most regions.

\section{B. Disadvantages of Earth/Loam}

i. Loam is not a standardised building material, because its characteristics differ from site to site.

ii. Shrinkage of the Loam mixtures when drying causes cracks. But this can be corrected by use of additives and reducing the clay and water content. 
iii. Loam is a poor water-resistant material. But earth walls can be protected by roof overhangs, damp-proof courses and surface finishes.

\section{Stabilization of Earth}

Earth stabilization refers to the addition of certain materials or substances such as bitumen, cement, lime etc to earth or loam to improve its properties and workability for building purpose and to eliminate its disadvantages [19]. This stabilized earth becomes improved building materials which are used widely in city suburbs and urban areas for meeting housing needs and it has been ascertained that stabilized earth is cheaper than other conventional materials used in building construction [20].

Because earth is both a traditional and modern building material, so also are earth stabilizers. Stabilization of earth depends on the type of loam or soil being dug out for construction. It should be noted that soil that must be suitable for use for building construction should not contain humus and plant matter. In addition, not all soils require external stabilizers because earth itself is the most common and effective stabilizer better than other forms of stabilizer. Accordingly, if the soil is too sandy, then clay is the best stabilizer for it and if it is too clayey, then sand is the best stabilizer needed for it.

However, traditional stabilizers include straw, chaff, cow dung, urine, sugar, plant juice, natural fibre, lime and oil especially coconut oil (this has now been replaced with waste engine oil which serves as waterproofing in both cement concrete and in mud walling). Also, Animal products like animal glue, blood, casein, urine and manure have been used as stabilizers of earth. Modern stabilizers are bitumen, lime and Portland cement which is the most popular but expensive and required much energy for production [15].

According to [1], one major reason for the addition of stabilizers is to check the shrinkage of mud in building; thus natural stabilizer such as fibres- animal or human hair, fibres from coconuts, sisal, agave or bamboo, needles from needle trees and cut straw, helps to reduce the clay content and absorbs certain amount of water into the fibre pores and increases the binding force of the mixture. However, there is a simple and traditional method of reducing shrinkage cracks in mud buildings which involves enhancing drying time. For instance, in the production of mud bricks, it is proper to allow them dry slowly and evenly by turning them upright, protecting them from direct sunlight and wind.

\section{Types of Earth Construcion}

According to [21], [1] [10] and [15], earth as a building material manifests in different forms which represents the diverse or types of earth construction. Based on the characteristics of mud to be used, the type of stabilizers and applied technology, loam can be in many forms. The most common ones are described briefly:

$i$. Cob: This is the certainly the first, oldest and simplest type of earth material for building in ancient times. Cob means a 'lump of rounded mass' which is produced by addition of little water to earth or loam to form a stiff large lump mud. This is roughly moulded with the hands into a vast elongated egg or ball shape called a cob. The size is about 30-
$40 \mathrm{~cm}$ long and $15 \mathrm{~cm}$ in diameter. A row of these cobs are stacked on top of each other and lightly pressed together with the hands or feet to form monolithic walls.

ii. Adobe: A-doe-bee as it is pronounced is also called sun dried brick or mud blocks/bricks and it is about the most popular form of earth walling for building purposes. Adobe is produced by filling mould of wood or metal (lately) with a wet loam manually. Simply put, it is mud blocks produced by throwing pasty loam mixture by hand into a mould, allowed to dry and used like burnt bricks or cement blocks.

iii. Rammed earth: This involves the throwing of compact or stiff mud into a prepared formwork and rammed or tampered manually with wooden or metal ram rod or mechanically completing one section to another repeatedly horizontally firstly and vertically after until the whole plan is completed. Thereafter, the formwork is removed, and the earth dries up naturally. Rammed earth is stronger but more expensive than cob.

iv. Compressed earth blocks: These are earth blocks produced by pouring slightly moistened loam into moulds of different forms and compressed either manually or mechanically using a motorized press to produce different types of blocks such as hollow blocks, interlocking blocks, solid blocks, etc and allowed to dry naturally. Compressed earth blocks production is a modern technology which combines features of traditional earthen technology and modern block making technology.

v. Wattle and daub: This is also known as' thrown loam or wet loam in-fill in skeleton structures'. This type of earth is one of the oldest in history which uses faintly wet mud as a plaster (daub) to cover thin panels (of cane, split bamboo or other stalks) that are woven together (wattle) and firmly held in place by wooden or bamboo posts and beams. Simply put, it is Plastic stabilized loam used to fill gaps in houses where the beams run horizontally across vertically laid wood or bamboo.

\section{Methodology}

The study area used is Adadama, Abi Local Government Area of Cross River State, Nigeria. The area has abundance of different kinds of earth with different colours such as white, red and black. Thus, the area has the highest number of houses constructed with earth of different colours in the entire Local Government Area. The method of study includes literature review, participant observation in earth building construction, questionnaire administration and use of focal group discussion. Earth building owners and artisans formed the focal group with which discussions were held.

Data was obtained through administration of structured questionnaires. A total number of 170 respondents representing head of households in Adadama community, Abi Local Government of Cross River State were randomly selected, and the questionnaires were administered through face-to-face contact with the respondents. The questionnaire contained close-ended questions designed to determine the socio-economic characteristics of respondents and the type of wall construction material used in buildings in the area. The 
data obtained was analyzed using simple statistical approach with results presented in tables.

\section{DISCUSSIONS AND FINDINGS}

Table 1 above; represent the occupation of the respondents numbered 170 who were randomly selected from the different streets that make up the study area. The table reveal that farmers account for the highest number of respondents representing $39.4 \%$ having buildings of their own. This is followed by traders with $21.2 \%$ and artisans with $20 \%$. From the rear of the table are others and Civil servants with $8.8 \%$ and $10.6 \%$ respectively.

\begin{tabular}{ccc}
\multicolumn{3}{c}{ TABLE 1: OCCUPATION OF RESPONDENTS } \\
\hline Occupation & Frequency & Percentage \\
\hline Farmers & 67 & 39.4 \\
Traders & 36 & 21.2 \\
Civil Servants & 18 & 10.6 \\
Artisans & 34 & 20.0 \\
Others & 15 & 8.8 \\
Others & 170 & 100 \\
Total & 170 & 100 \\
\hline
\end{tabular}

Source: Authors' fieldwork (2020).

Conversely, Table 2 present the type of wall material used in buildings in the study area. Out of the 170 buildings sampled, 135 buildings $(85.3 \%)$ in the area are constructed with mud, while only $14.7 \%$ (25 buildings) account for cement block wall construction. From the 135 buildings made of mud, 66 are with red mud, 44 have white mud and 35 black mud. This reveals that the study area demonstrates high value and relevance to the use of mud for their building construction.

\begin{tabular}{ccc}
\multicolumn{2}{c}{ TABLE 2: BUILDING WALL CONSTRUCTION MATERIAL $(\mathrm{N}=170)$} \\
\hline Occupation & Frequency & Percentage \\
\hline Mud (white) & 44 & 25.9 \\
Mud (red) & 66 & 38.8 \\
Mud (black) & 35 & 20.6 \\
Cement block & 25 & 14.7 \\
Total & 170 & 100 \\
\hline
\end{tabular}

Source: Authors' fieldwork (2020).

However, discussion with the focal group reveal that virtually all the adult's male who are married have their own buildings. On the possibility of an adult male, married without a building, the group said it was almost impossible as it was one major prequalification for marriage in the community. It was also gathered that the process of building a house was made simple and cheap with mud due to availability of abundant earth, cheap material and free labour for construction because of age grade involvement in helping any would-be house owner construct a building in the area.

\section{Processes of Construction of Earth buildings Using Adobe}

Location of proposed building site: the first thing is to locate a site for the proposed mud building similar with the normal conventional practice. Identify the highest part of the land to site your proposed building if the land is sloppy or simply avoid the lower part of the land. Alternatively, you could create a trench to divert water away from your building.
Preparation of the Loam/Mud block: This should be done within the area for the proposed building for ease of usage during the construction proper. Thereafter, depending on the area and soil type available, the soil is dug deep down to avoid top organic matters. The loam is mixed it water, then straw or any other stabilizer is added to form a paste loam which is then thrown into a prepared mould and allowed to dry gradually to produce adobe.

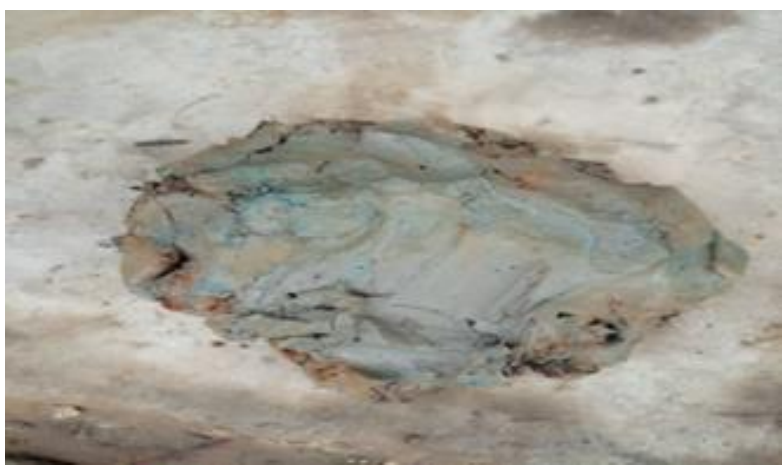

Fig. 1. White loam with stabilizer

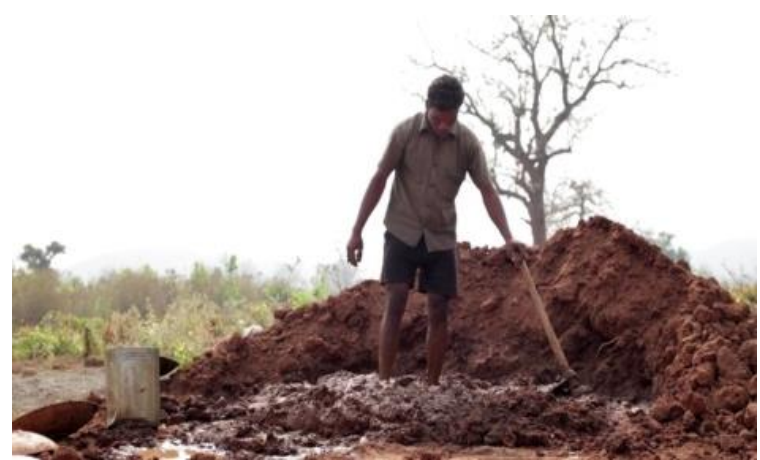

Fig. 2. Preparation of loam

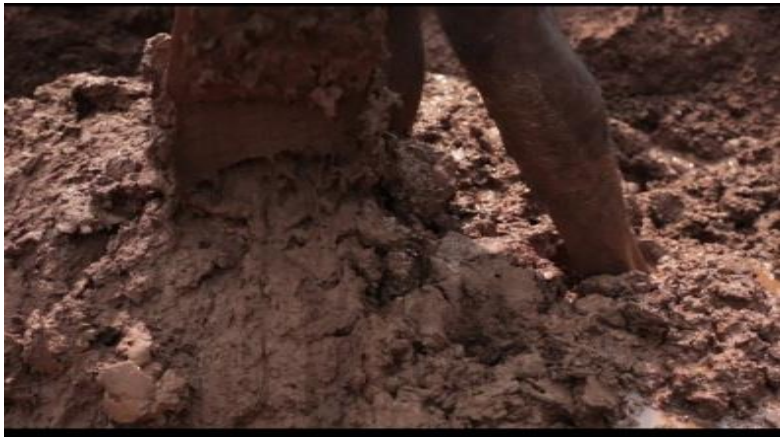

Fig. 3. Preparation of loam with stabilizers added Source: Authors' fieldwork, 2020

Foundation: Foundation trench is dug based on the floor plan available and depending on the size of the mud blocks (Fig. 4 and 5). The trench should be about the thickness of the basement wall to avoid in-filling to prevent water soaking into the mud wall. A mixture of sand, cement, stone and water produces concrete mix for foundation work.

Laying Mud Blocks: Before the blocks are laid, mud mortar has to be prepared. This is done by making use of the same soil type that was used for the blocks; reduce the clay content to avoid cracks; sieve the loam to remove gravel and stones; then use a double proportion of the same stabilizers used for the blocks. After the mortar preparation, the blocks 
are laid using a thin layer of the loam mortar to eliminate shrinkage cracks as in Fig. 6 and 7.

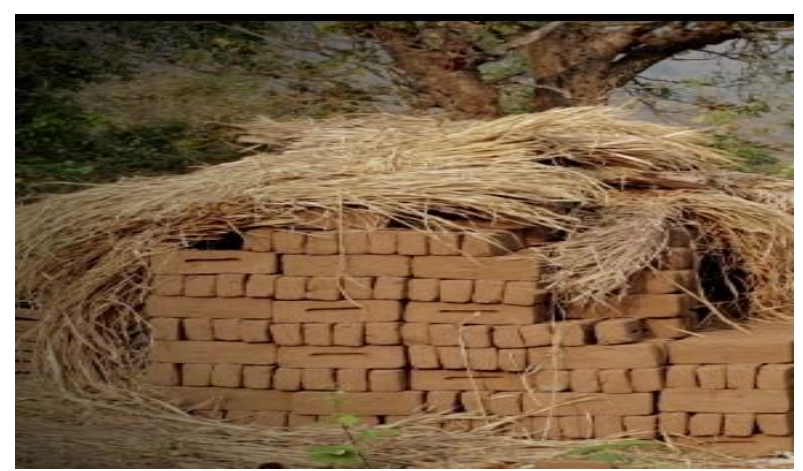

Fig. 4. white adobe blocks.

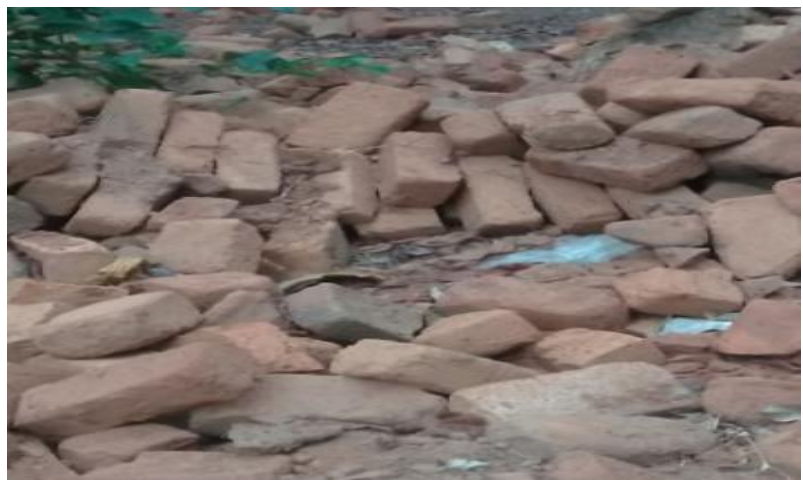

Fig. 5. white adobe blocks.

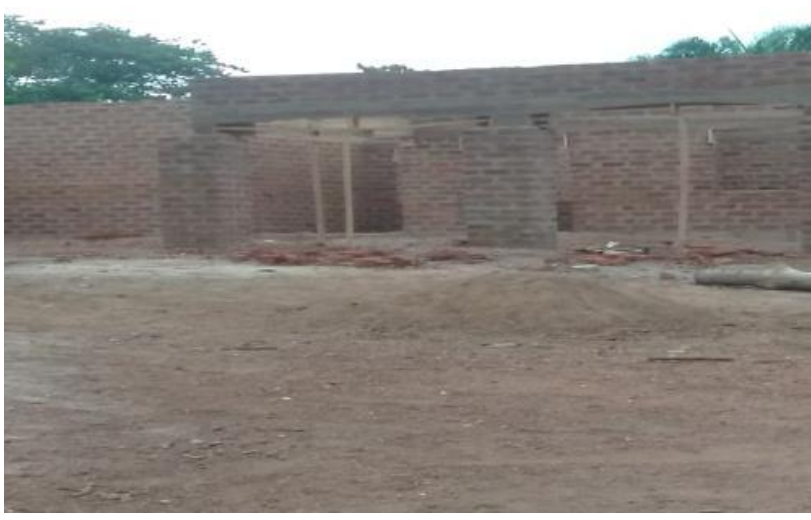

Fig. 6. Mud block laying/setting.

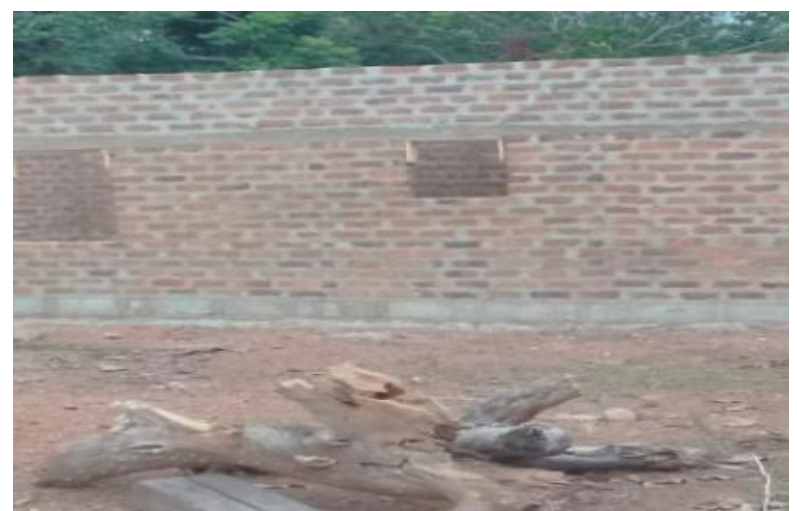

Fig.7. Mud block laying/setting.

Source: Authors' fieldwork, 2020.

Surface Treatment: Mud block masonry usually have irregular or rough surface which require surface treatment in order to smoothen it and make it more aesthetically appealing. The methods for mud finishes include plastering with loam plaster mixed with stabilizer such as cement, lime or cow dung. Alternatively, the surface can be finished by applying a wash of loam slurry stabilised with lime or limecasein. These two methods have been found to have effect on balance internal air humidity and wall's surface stability. Thus, the best option is to consolidate the surface. This consolidation means using a metal trowel with high pressure to rub the surface of the wall when it is moist and faintly pliable. This help to increase the degree of weather resistance of mud wall constructions.

\section{CONCLUSION}

Building construction using earth or mud as a walling material has proven to be very economical, environmentally friendly and ideal alternative to the conventional building materials. Mud is available in almost everywhere and its advantages make it possible for not just the poor but also the middle income group to build houses of the own. Mud can help solve the housing crises or deficit being experienced in developing countries especially in the absence of social housing scheme. The simplicity in the mud technology makes it more indigenous thereby strengthening the cultural aspect of housing.

However, this study has shown that the limitations of mud which hitherto was the reason for its non-acceptability can be overcome through stabilization and other appropriate technology. The government of developing countries only need to encourage and support the use of mud for building by incorporating it in the housing policy and also constructing some local authority building projects with mud for greater acceptability.

\section{ACKNOWLEDGMENT}

The authors wish to thank the people of Adadama, Abi Local Government Area of Cross River State, Nigeria for their cooperation and understanding. Their candid responses as respondents and focal group members contributed immensely to the success of this research. The contributions of the artisans in the study area are also highly appreciated.

\section{REFERENCES}

[1] G. Minke, 'Building with Earth Design and Technology of a Sustainable Architecture.' Basel • Berlin • Boston: Birkhäuser Publishers for Architecture; 6th Edition, 2006.

[2] A. A. Akeju, 'Challenges to providing affordable housing in Nigeria,' Proceedings of 2nd Emerging Urban Africa International Conference on Housing Finance in Nigeria, Abuja, Nigeria, 17-19th October, 2007.

[3] A. E. Ega and C. Job, 'Traditional earth plasters and renders in Nigeria: A preliminary study,' Journal of Environmental Sciences University of Jos. Vol. 15: pp.1-6, 2011.

[4] E. E. Atamewan and R. E. Olagunju, 'Sustainable Low-income Housing and Practicable Minimum Design Standards in Bayelsa State, Nigeria,' Journal of Sustainable Architecture and Civil Engineering. Vol. 3, no.20, pp. 14-24, 2017.

[5] P. Awofeso, 'One out of two Nigerians now lives in a City: There are many problems but one solution,' World Policy Journal, 27:67, 2010.

[6] S. V. Doraisamy, Z. A. Akasah and R. Yunus, 'A Review on Abandoned Construction Projects: Causes and Effects,' Applied Mechanics and Material, Vol. 773-774; pp. 979-983, 2015. 
[7] M. A. Tijani and W. Ajagbe. 'Professional views on the causes and effects of construction projects abandonment in Ibadan Metropolis,' Nigeria. Ethiopian Journal of Environmental Studies and Management. Vol. 9 no.5, pp. 593-603, 2016.

[8] D. Mac-Barango, 'Construction Project Abandonment: An Appraisal of Causes, Effects and Remedies,' World Journal of Innovation and Modern Technology. Vol. 1, no. 1, 2017.

[9] A. A, Daniel, G. K, Benjamin and J. O. Tali, ‘Adopting Stabilized Earth Construction to address Urban Low-cost Housing Crisis in Jos, Nigeria,' Journal of Ergonomics Studies and Research. Vol.1 no.1; pp. $1-10,2018$

[10] G. S. Sruthi, "Mud Architecture," International Journal of Innovative Research in Science, Engineering and Technology. Vol. 2, no. 1, 2013.

[11] Y. A. Al-Sakkaf, 'Durability Properties of Stabilized Earth Blocks,' Unpublished doctoral dissertation. Universiti Sains, Malaysia, 2009.

[12] A. O. Olotuah and A. A. Taiwo, 'Housing the Urban Poor in Nigeria through Low-Cost Housing Schemes,' International Journal of Physical and Human Geography. Vol. 1, no.3, pp. 1-8, 2013.

[13] O. Arayela, 'Developing Appropriate Housing Construction Technology for Medium and Low Income Earners in Africa: Focus on Nigeria,' Africa Union of Architects Conference Proceedings. Talos Press, pp. 10-11, 2005.

[14] A. O. Olotuah, 'Recourse to Earth for Low-Cost Housing in Nigeria,' Building and Environment. Vol. 37, no. 1, pp. 123-129, 2002.

[15] B. Laurie, 'Mud,' India: Penguin Books Ltd. pp. 1- 28, 1991.

[16] M. Jovanović, A. Mirić, G. Jovanović and A. M. Petronijević, 'Earth as a Material for Construction of Modern Houses,' FACTA UNIVERSITATIS Series: Architecture and Civil Engineering, Vol.16, no. 2 , pp. $175-188,2018$

[17] H. Niroumand, M. F. M. Zain, M. Jamil and S. Niroumand, 'Earth Architecture from Ancient until Today,' 2nd Cyprus International Conference on Educational Research, (CY-ICER 2013). Procedia Social and Behavioral Sciences. Vol. 89; pp. 222-225, 2013.

[18] O. O. Odunjo, S. B. Oladimeji and S. A. Okanlawon, 'Public Acceptability of Burnt Brick for Mass Housing Projects in Ilorin, Nigeria,' Civil and Environmental Research. Vol. 7, no. 3, pp. 1-9, 2015.

[19] J. Struebur, V. Harns, E. Meyer, E. Carter, E. Maweza and M Matshaya, “An Energy Efficient House for under \$3,000," Proceedings of the 2004 American Society for Engineering Education Annual Conference and Exposition, pp. 1106 - 1115, 2004

[20] M. S. Zami and A. Lee, 'Inhibitors of adopting stabilized earth construction to address urban low cost housing crisis: An understanding by construction professionals,' Journal of Building Appraisal, Vol. 6, pp. 227-240, 2011.

[21] N. Hamed, M. F. M, Zain and M. Jamil, 'Various Types of Earth Buildings,' Procedia - Social and Behavioral Sciences, Vol. 89, 2013.S Chen, B. Mulgrew, and P. M. Grant, "A clustering technique for digital communications channel equalization using radial basis function networks," IEEE Trans. on Neural Networks, vol. 4, pp. 570-578, July 1993.

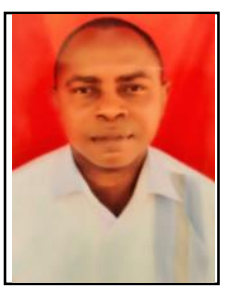

Atamewan, Eugene Ehimatie, was born in Edo State of Nigeria. He holds a Ph.D. Degree in Architecture, Federal University of Technology, Minna, Nigeria in 2018; M.Sc (Arch) in 2001; B.Sc(Arch) in 1999 both from Ambrose Alli University Ekpoma, Nigeria.

$\mathrm{He}$ is currently a Senior lecturer/Research fellow, Department of Sustainable Architecture \& Urban Design, Faculty of Architecture, Cross River University of Technology, Calabar, Nigeria. He joined the services of the University in 2007 . His wealth of experience cut across architectural practice, teaching and community service. Dr. Atamewan is a registered Architect with Architects Registration Counci of Nigeria (ARCON). He is a member of the Nigerian Institute of Architects (NIA), Association of Architectural Educators in Nigeria (AARCHES) and Nigerian Institute of Management (NIM).

His area of interest covers multidisciplinary research on construction and built environment, building maintenance, sustainable housing, socio-cultural Architecture and housing standards. This scholar has several local and international published journal articles in areas such as housing, building maintenance, Landscape planning and sustainable design to his credit. He is particularly interested in the intersections of architecture, culture and the environment. His seminars, lectures and designs articulate his advocacy for housing delivery for the poor in developing Countries. He is also a reviewer to some local and international journals of repute.

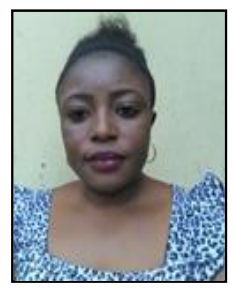

Otire, Grace Atah (Mrs), was born on 3rd January, 1984 and hail fromYala Local Government Area of Cross River State, Nigeria. She holds a Bachelor of Technology Degree in Architecture, Cross River University of Technology, Calabar, Nigeria in 2014 National Diploma in architectural Technology from The Polytechnic, Calabar in 2005. She is currently a Master's Degree student in Architecture, Cross River University of Technology, Calabar, Nigeria.

She is a staff of the University of Calabar, Nigeria as a Technologist in the Faculty of Environmental Sciences since 2019. Otire is a graduate member of the Nigerian Institute of Architects

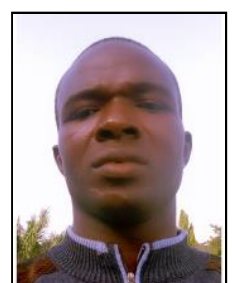

Egbuluwa, Innocent Ibi, was born on 16th August, 1987 and hail from Adadama, Abi Local Government Area of Cross River State, Nigeria. He holds a Bachelor of Technology Degree in Architecture, Cross River University of Technology, Calabar Nigeria in 2016. He is currently a Master's Degree student in Architecture, Cross River University of Technology, Calabar, Nigeria.

He currently works with a private Architectural Firm, Mekiks Associates, Calabar, Nigeria as a trainee Architect since 2018. Egbuluwa is a graduate member of the Nigerian Institute of Architects (GMNIA). Her area of architectural interest is sustainable Architecture and Urban 